\title{
Lock-in thermography and fatigue limit of metals
}

\author{
by J.-C. Krapez, D. Pacou and G. Gardette \\ ONERA, DMSE, BP 72, F-92322 CHÂTILLON-Cedex, France.E-mail: krapez@onera.fr
}

\begin{abstract}
:
Thermography was performed on stainless steel $316 \mathrm{~L}$ and aluminium alloy 7010 samples as they were submitted to a sinusoïdal mechanical stress (traction/compression). For each stress amplitude value the temperature data were recorded in $5 \mathrm{~s}$. A specific signal demodulation procedure was used to extract the first two Fourier components and the mean temperature rise. From their particular dependence on the stress amplitude, characteristic stress values could be derived. In some instances, these values are very close to the fatigue limit of the considered material.
\end{abstract}

\section{Introduction}

It is known for some years that there is a clear correlation between the fatigue limit of some metallic materials, in particular some steel materials, and the appearance of heat dissipation measurable by IR thermography [1-3]. M.P. Luong proposed to evaluate this fatigue limit through the measurement by thermography of the mean thermal energy dissipated during a given number of cycles [1]. More recently it was suggested to use different harmonics of the modulated temperature to determine the requested mechanical parameter [4-8].

We recently performed some fatigue tests on a series of XC48 steel samples (tensile/compression stress) and simultaneously measured with a focal plane array camera the modulated surface temperature [7,8]. Through lock-in data processing we got, for each stress amplitude value, a series of images corresponding to the temperature linear «drift » (expressed in $\mathrm{mK}$ per cycle), the amplitude of the temperature component synchronous at the mechanical frequency $f$ and the one at the second harmonic $2 f$.

For a particular value of the stress amplitude, we observed a change in the thermomechanical behaviour of the material: the mean temperature of the sample started to grow significantly, the slope of the temperature component at frequency $f$ suddenly moved to a higher value, and a temperature component at $2 f$ emerged out of noise. All three phenomena occurred at roughly the same stress amplitude value that corresponded fairly well to the actual fatigue limit of XC48. With lock-in thermography three criteria are thus available: the emergence of a temperature «drift », a change in the slope of the thermoelastic curve (the curve of the $f$-component of the temperature vs. the stress amplitude), and the emergence of a Fourier component a $2 f$.

As compared to the conventional temperature increase measurement [1-3], lock-in thermography provides a better immunity to environmental noise. The advantage of the thermal approach is that the evaluation of the fatigue limit requires only one sample and just a few hours for measurement and data processing.

In this paper we will present the results obtained with a stainless steel material and with an aluminium alloy that is used in the aeronautic industry.

\section{Tested materials}

We considered stainless steel $316 \mathrm{~L}$ (AISI) and the aluminium alloy 7010 . The dog-bone specimens were $3 \mathrm{~mm}$ thick. The central part, $20 \mathrm{~mm}$ long, had a constant width of $25 \mathrm{~mm}$. The specimens were grinded in order to delay crack initiation. 
The front face of the samples was black painted in order to increase the surface emissivity. The coating thickness was sufficiently thin (typically 20 microns) to have a negligible influence on the temperature data at the considered modulation frequency.

\section{Mechanical tests}

The samples were submitted to a sinusoïdally modulated stress for a few cycles. We applied successive traction and compression or a repeated traction. Two different values were considered for the ratio between minimum and maximum stress: $R_{\sigma}=-1$ or 0 .

The chosen frequency was relatively low: $2 \mathrm{~Hz}$. At each stress level, the specimen was loaded only for a few tens of cycles. By this way the irreversible damage occurring at a given stress amplitude level could be considered of low impact on the measurements performed later at higher stress levels. The same specimen could thus be used to generate the curve of thermal signal vs. stress amplitude until failure.

\section{Thermography measurement and data processing}

The specimen surface temperature measurement was performed with an Amber IR focal plane array camera (128x128 pixels, $109 \mathrm{~Hz}, \mathrm{NETD}$ at $\left.30^{\circ} \mathrm{C}: 7 \mathrm{mK}\right)$.

The camera field was about $50 \mathrm{~mm} \times 50 \mathrm{~mm}$. IR images were stored on a memory board, its capacity corresponds to 492 images. We simultaneously stored the reference signal necessary for the demodulation procedure. This signal was the one sent to the servocontrolled hydraulic system of the testing machine.

Signal processing was performed for each pixel. It consists in parameter identification based on least-squares minimisation [8, 9]. Present version of the software is based on the cost function:

$$
J=\sum_{i=1}^{n}\left(T_{\exp }\left(t_{i}\right)-T_{\bmod }\left(t_{i}\right)\right)^{2}
$$

where $T_{\exp }\left(t_{i}\right)$ is the experimental temperature value at time $t_{i}$, and $T_{\bmod }\left(t_{i}\right)$ is the model temperature defined by:

$$
T_{\text {mod }}(t)=T_{0}+\Delta T f t+T_{1} \sin \left(\omega t+\varphi_{1}\right)+T_{2} \sin \left(2 \omega t+\varphi_{2}\right)
$$

$f=\omega / 2 \pi$ is the stress frequency, $T_{0}$ is the temperature level when the temperature recording starts, $\Delta T$ is the mean rise of the temperature per cycle, $T_{1}$ and $\varphi_{1}$ are the amplitude and phase of the first Fourier component, $T_{2}$ and $\varphi_{2}$ are the same for the second component.

Six parameters are calculated at each measurement site, i.e. at each pixel. Three of them are used in present application: $\Delta T, T_{1}$, and $T_{2}$.

When the material is stressed well below the fatigue limit, $\Delta T$ and $T_{2}$ are expected to vanish. The third component, i.e. the synchronous component $T_{1}$ at frequency $f$ actually describes the thermoelastic effect:

$$
T_{1}=\frac{\alpha T_{0}}{\rho C_{\varepsilon}} \sigma
$$

where $\alpha$ is the coefficient of linear thermal expansion, $\rho$ is density, $C_{\varepsilon}$ is the specific heat under constant strain, and $\sigma$ is the stress amplitude (in fact this relation between two amplitude variables hinders the fact that temperature and stress have $180^{\circ}$ phase difference). 
Most previous works on the application of thermography to the fatigue limit focussed on a temperature increment that is equivalent to $\Delta T$ [1-3]. In [4,5] it was suggested to analyse second and higher harmonics. The interest of using $T_{1}$ was simultaneously presented in [6] and [7]. In [7, 8] we showed, based on results obtained with steel XC48, that all three measured parameters $\Delta T(\sigma), T_{1}(\sigma)$, and $T_{2}(\sigma)$ may give valuable insight on the fatigue limit.

Practically, we applied a sinusoïdally modulated stress with an amplitude $\sigma$ ranging from $50 \mathrm{MPa}$ to a value leading soon to failure, i.e. about 250 or $400 \mathrm{MPa}$, depending on the material. For each stress amplitude value, a series of 10 cycles was captured by the IR camera. Data processing was performed thereafter to get the images of $\Delta T, T_{1}$, and $T_{2}$. To improve signal to noise, we averaged the temperature maps in the centre of the sample or in a region showing eventually a particular thermal behaviour (sometimes high temperature values could be observed just before failure; the corresponding region undoubtedly reveal the origin of the critical damage).

\section{Experimental results with stainless steel $316 \mathrm{~L}$}

We reported in fig. 1 the results corresponding to a $316 \mathrm{~L}$ sample. The load ratio was $R_{\sigma}=-1$ (alternating traction and compression). In fig. 1a we plotted $\Delta T(\sigma)$. There was virtually no heating (in the mean sense) as long as the stress amplitude was lower than 200 $\mathrm{MPa}$. Then, the sample progressively heated during each cycle. During the test that just preceded the failure, i.e. at $260 \mathrm{MPa}, \Delta T$ reached about $60 \mathrm{mK} / \mathrm{cycle}$. We performed a linear regression on the first points revealing a significant heating. The stress amplitude obtained by extrapolating down to $0 \mathrm{mK} /$ cycle is $219+/-7 \mathrm{MPa}$ (confidence interval at +/$2 \sigma)$. This characteristic value corresponds to the stress amplitude below which no measurable dissipation is expected.

In fig. $1 \mathrm{~b}$ we plotted the fundamental Fourier component of temperature vs. stress amplitude, $T_{1}(\sigma)$. The curve is nearly linear as predicted by eq. 3 . The difference between $T_{1}(\sigma)$ and the linear trend evaluated from the first points is plotted in fig. 1c. This figure clearly shows that, when the stress amplitude is higher than about $206+/-3 \mathrm{MPa}$, the thermoelastic law in eq. 3 is no longer valid.

In fig. $1 \mathrm{~d}$ we plotted $T_{2}(\sigma)$. The rise of the second Fourier component seems to be more gradual than with $\Delta T(\sigma)$. Anyway, from a linear regression based on the points showing a clear presence of a harmonic at $2 f$, followed by an extrapolation down to $0 \mathrm{mK}$, we found a characteristic stress amplitude value of $190+/-14 \mathrm{MPa}$.

We thus found three characteristic stress values that are relatively close one to the other. The fatigue limit of $316 \mathrm{~L}$, in the particular case of $R_{\sigma}=-1$, is $222 \mathrm{MPa}$ [10]. This value is relatively close to the three values we mentioned before.

Other measurements were performed with a load ratio of 0 . The results are summarised in fig. 3 where we plotted the characteristic stress values inferred from $\Delta T, T_{1}$, and $T_{2}$ (we reported the maximum stress, not the amplitude). These stress values are higher than before, i.e. between 245 and $320 \mathrm{MPa}$. Presently, the only data we have for this batch of $316 \mathrm{~L}$ samples, and for $R_{\sigma}=0$, is the endurance limit at $\mathrm{N}=2 \cdot 10^{5}$ cycles: $405 \mathrm{MPa}$ [10]. The so-called fatigue limit, i.e. the asymptotic level of the Wöhler curve must be lower than $405 \mathrm{MPa}$. Whether the characteristic stress values revealed by thermography are close to this fatigue limit is still to be verified. 


\section{Experimental results with aluminium alloy 7010}

Measurements with $R_{\sigma}=-1$ were also performed on two 7010 aluminium specimens. The curves describing $\Delta T(\sigma), T_{1}(\sigma)$, and $T_{2}(\sigma)$ are plotted in fig. 2, together with the difference between $T_{1}(\sigma)$ and its initial linear fit.

One can notice important differences with steel 316L. First, dissipation was hardly detected in aluminium: a temperature drift was detected just before failure, i.e. far beyond the fatigue limit. It is thus impossible to find out any characteristic stress value from $\Delta T(\sigma)$ (see fig. 2a). Secondly, a Fourier component at $2 f$ is well detected, however its rise with the stress level starts very progressively and very early. The characteristic stress value that is found from a linear regression on the right part of the curve $T_{2}(\sigma)$ is $108+/-9 \mathrm{MPa}$ (see fig. $2 \mathrm{~d})$. We have to admit that the extrapolation down to $0 \mathrm{mK}$ is questionable, due to the smooth shape of $T_{2}(\sigma)$ : at which stress amplitude does $T_{2}$ really emerge ?

On the other hand, a sharper change can be observed on the curve of $T_{1}(\sigma)$ residuals (fig. 2c): it is clear that below $225+/-14 \mathrm{MPa}, T_{1}(\sigma)$ is well approximated by the classical law reported in eq. 3 and that for a higher stress amplitude the material behaves differently.

The fatigue limit of aluminium 7010 was measured conventionally and an estimation of $210+/-20 \mathrm{MPa}$ was found in the particular case of $R_{\sigma}=-1$. This shows that the characteristic stress value as provided by $T_{1}(\sigma)$ curve is in close relation with the fatigue limit of the considered aluminium alloy.

\section{Conclusion}

We considered two other materials to assess the feasibility of using lock-in thermography for a rapid evaluation of the fatigue limit. Measurements once performed on XC48 steel with $R_{\sigma}$ at -1 and 0 have shown that all three curves $\Delta T(\sigma), T_{1}(\sigma)$, and $T_{2}(\sigma)$ had peculiarities that are closely related to the fatigue limit of this material. With aluminum alloy 7010, $\Delta T(\sigma)$ appears to be useless: dissipation is too low. $T_{2}(\sigma)$ rises to important values while the stress amplitude increases; however the slope change is too slow to provide a safe and easy indication about an eventual thermomechanical modification. On the other side, $T_{1}(\sigma)$ departs from the Kelvin law at a well-defined stress amplitude that is close to the real fatigue limit (the one evaluated at $\mathrm{N}=2 \cdot 10^{7}$ cycles).

In the case of stainless steel 316L, for $R_{\sigma}=-1$, all three parameters $\Delta T(\sigma), T_{1}(\sigma)$, and $T_{2}(\sigma)$ give satisfactory results. For $R_{\sigma}=0$, they however all provide an underestimation of the fatigue limit (the known value corresponds to only $N=2 \cdot 10^{5}$ cycles, the real underestimation is thus unavoidably lower than it appears in fig. 3).

\section{References}

[1] LUONG, M.P., "Infrared thermography of fatigue in metals", SPIE, vol. 1682, 1992, p 222233

[2] KURILENKO, G.A., "Advanced infrared examining of the metals fatigue", Proc. Workshop Advanced Infrared Technology and Applications, Capri (It.), Sept. 19-20, 1995, Atti della Fondazione G. Ronchi, anno LI, p 253-262, 1996

[3] BERARD, J.-Y., RATHERY, S. and BERANGER, A.-S., "Détermination de la limite d'endurance des matériaux par thermographie infrarouge", Matériaux et Techniques, $n^{\circ} 1-2$, 1998, p 55-57 
[4] BREMONT, P. and POTET, P., D, "Démodulation synchrone des images thermiques. Application à l'analyse expérimentale des structures", Journée de la Soc. Franç. des Thermiciens, Thermographie Quantitative, 7 déc. 1994

[5] BREMONT, P., " La thermographie infrarouge pour voir les contraintes", Mesures, vol. 653, 1996, p 53-56

[6] BONNET, C., LIEURADE, H.P., MERRIEN, P., BREMONT, P., "Evaluation des potentialités de la thermographie infrarouge pour la détermination rapide de la limite d'endurance des matériaux", Journées d'étude CETIM, Senlis (France), June 22-23, 1999

[7] KRAPEZ, J.-C., "Métrologie thermique : des matériaux jusqu'aux structures”, Journées d'étude CETIM, Senlis (France), June 22-23, 1999

[8] KRAPEZ, J.-C., PACOU, D. and BERTIN, C., "Application of lock-in thermography to rapid evaluation of fatigue limit in metals", 5th Int. Workshop on Advanced Infrared Techn. and Appl., Venezia (Italy), Sept. 29-30, 1999

[9] KRAPEZ, J.-C., "Compared performances of four algorithms used for digital lock-in thermography”, Quantitative Infrared Thermography, QIRT 98, Lodz (Pol.), Sept 7-10, 1998.

[10] CHABOCHE, J.-L., KACZMAREK, H. and RAINE, P., "Sur les effets d'interaction de l'écrouissage et de l'endommagement dans l'acier 316L", La Recherche Aérospatiale, $\mathrm{n}^{\circ} 3$, 1980, p 177-196
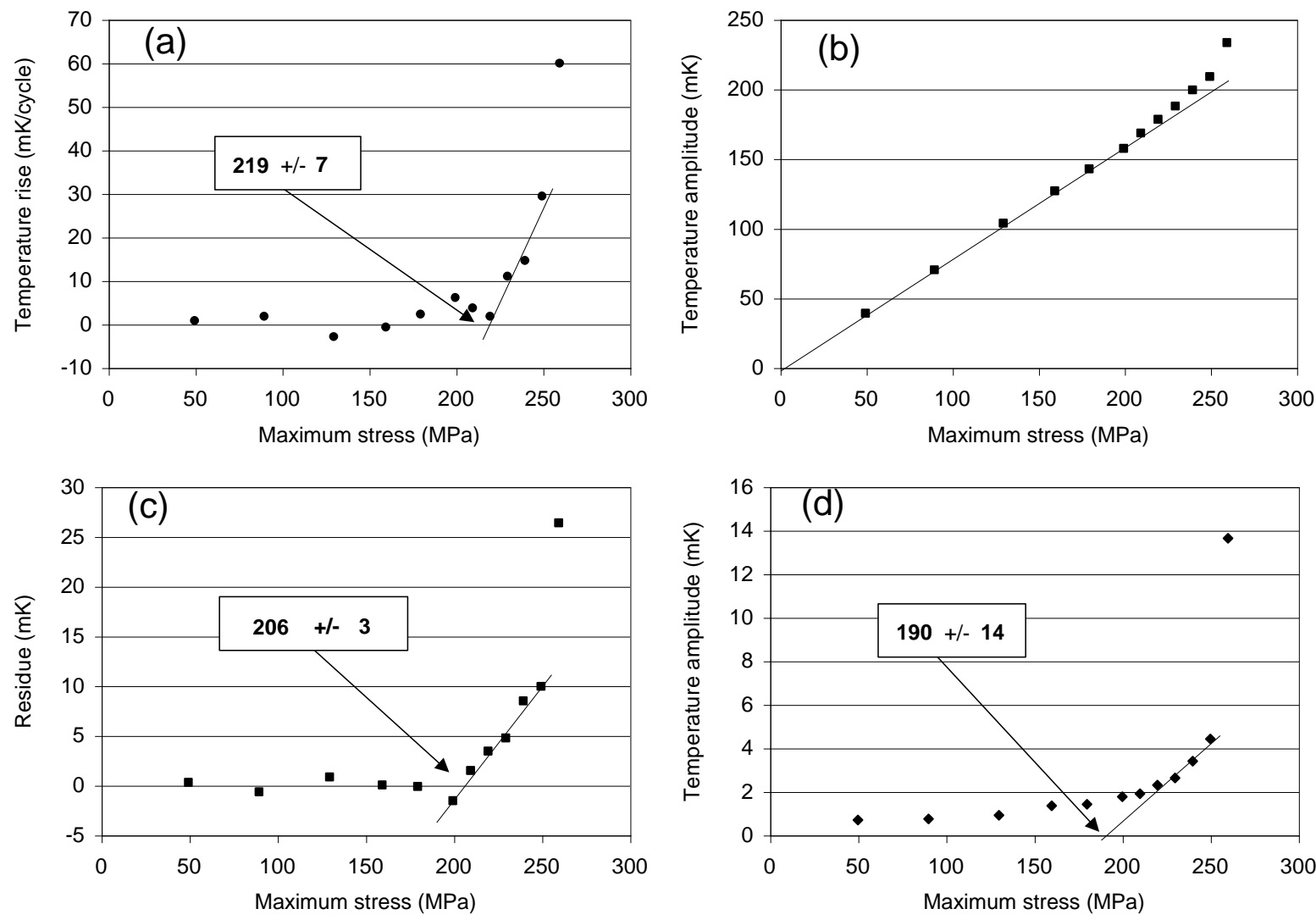

Figure $1: 316 \mathrm{~L}$ stainless steel sample submitted to a fatigue test at frequency $f=2 \mathrm{~Hz}$ (load ratio: $R_{\sigma}$ $=-1$ ). Lock-in thermography provides an image of $T_{1}$, the temperature component at frequency $f$, an image of $T_{2}$, the component at $2 f$, and an image of $\Delta T$, the mean temperature rise. Plots of: $\Delta T(\sigma)$ (a), $T_{1}(\sigma)$ (b), the difference between $T_{1}(\sigma)$ and the linear fit of its initial part (c), and $T_{2}(\sigma)$ (d). Each point is the result of 10 cycles. Failure occurs during the test at $270 \mathrm{MPa}$. 

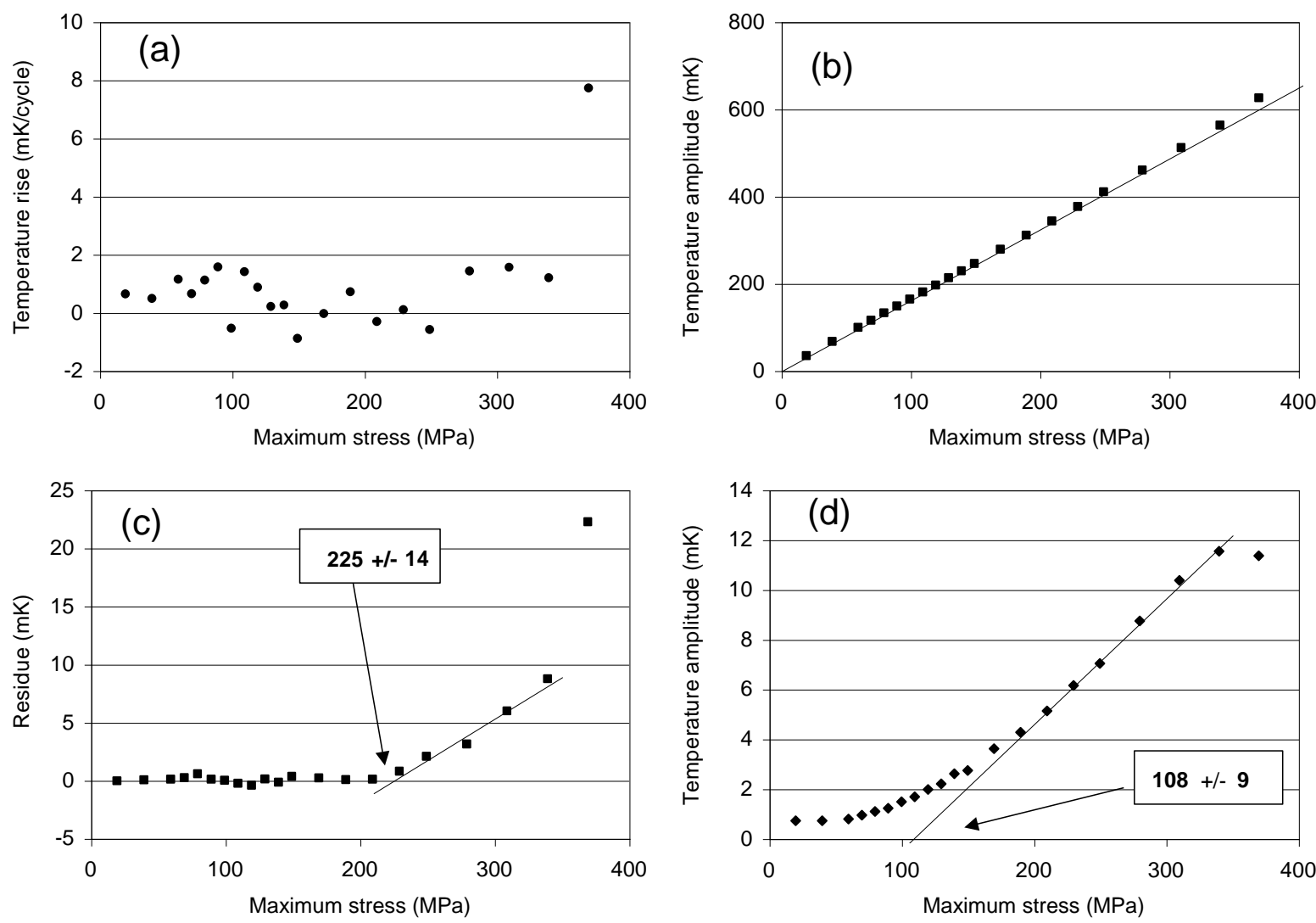

Figure 2 : Same with a 7010 aluminium alloy specimen. Failure occurs during the test at $400 \mathrm{MPa}$.
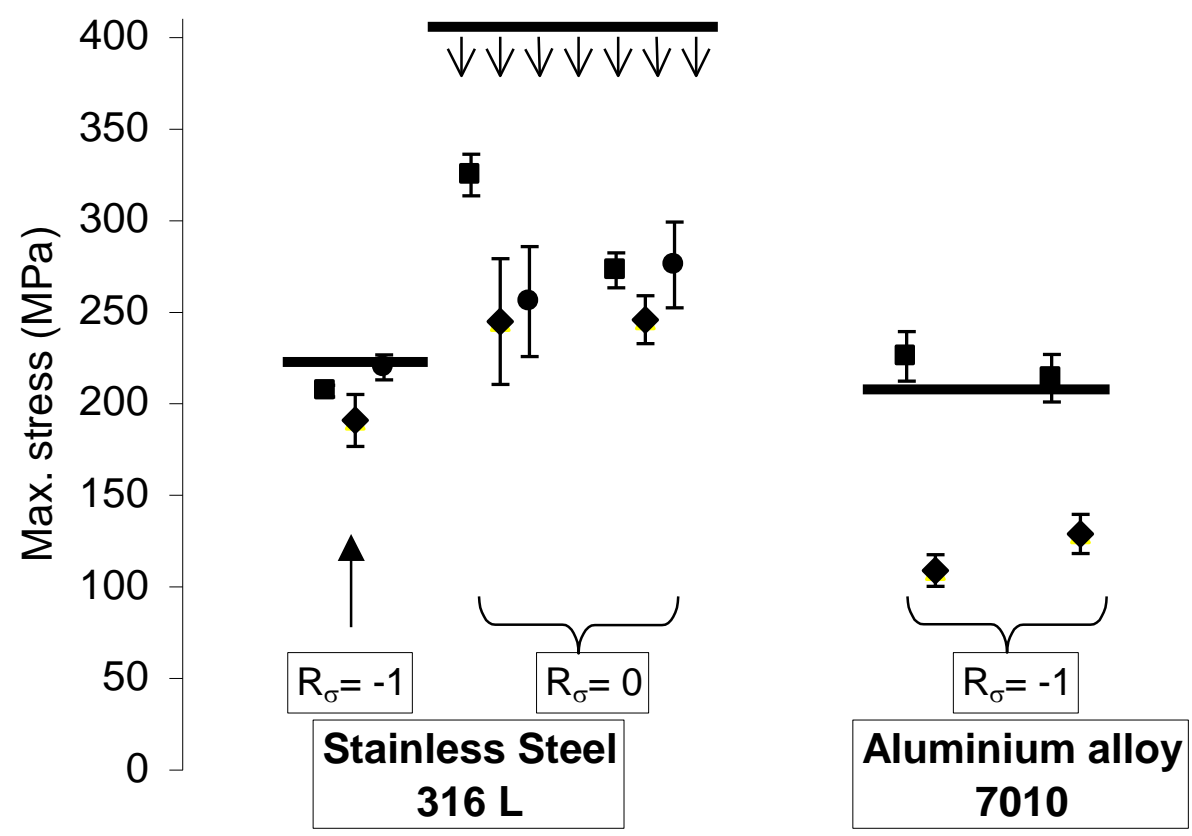

Figure 3 : Summary of thermographic results with $316 \mathrm{~L}$ and 7010 samples. Characteristic stress values as inferred from $\Delta T(\sigma)$ (diamonds), from $T_{1}(\sigma)$ (squares), and from $T_{2}(\sigma)$ (circles). Three horizontal lines indicate the known values of the fatigue limit corresponding to the considered load ratio values $R_{\sigma}=-1$ and $R_{\sigma}=0$. (the data for steel $316 \mathrm{~L}$ at $R_{\sigma}=0$ is the endurance limit for only $\mathrm{N}=2 \cdot 10^{5}$ cycles, the true fatigue limit is thus lower than indicated by the horizontal line). 